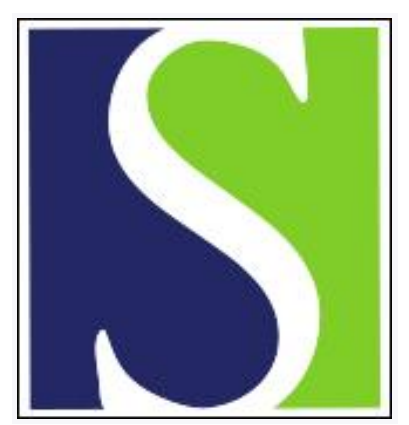

Scand J Work Environ Health 2012;38(1):65-69

https://doi.org/10.5271/sjweh.3176

Published online: 17 Jun 2011, Issue date: Jan 2012

Parkinson's disease among gardeners exposed to pesticides a Danish cohort study

by Kenborg L, Lassen CF, Lander F, Olsen JH

Affiliation: Institute of Cancer Epidemiology, Danish Cancer Society, Strandboulevarden 49, 2100 Copenhagen, Denmark. kenborg@cancer.dk

Refers to the following texts of the Journal: 2000;26(4):359-362 2007;33(6):465-469 1986;12(2):97-107 2011;37(5):427-436

The following article refers to this text: 2017;43(3):197-209

Key terms: cohort study; Denmark; epidemiology; gardener; gardening; occupational health; occupational health; Parkinson's disease; pesticide

This article in PubMed: www.ncbi.nlm.nih.gov/pubmed/21687921

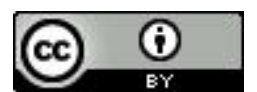




\title{
Parkinson's disease among gardeners exposed to pesticides - a Danish cohort study
}

\author{
by Line Kenborg, MSc, ${ }^{1}$ Christina Funch Lassen, PhD, ${ }^{1}$ Flemming Lander, PhD, ${ }^{2}$ Jergen H Olsen, DMSc ${ }^{1}$
}

Kenborg L, Lassen CF, Lander F, Olsen JH. Parkinson's disease among gardeners exposed to pesticides - a Danish cohort study. Scand J Work Environ Health. 2012;38(1):65-69. doi:10.5271/sjweh.3176

\begin{abstract}
Objective Several studies have found positive associations between exposure to pesticides and Parkinson's disease. As Danish gardeners have had frequent, intensive exposure to pesticides, the aim of this study was to investigate their risk for Parkinson's disease.

Methods The cohort was comprised of 3124 male members of the Danish Union of Gardeners on 1 April 1975 Hospital register data were used to follow them for a primary diagnosis of Parkinson's disease during 1977-2008 and to calculate standardized hospitalization rate ratios (SHR) for this disease among gardeners and the general Danish population for comparison. Data from the Danish Cancer Registry were used to calculate standardized incidence rate ratios (SIR) for smoking-related cancers among gardeners and the general population.

Results The SHR for Parkinson's disease among gardeners was close to that of the general population [1.14, $95 \%$ confidence interval (95\% CI) $0.76-1.65]$. In a birth cohort analysis, a downward trend was observed, with the highest risk among gardeners born before 1915 (SHR 1.55, 95\% CI 0.77-2.77). The SIR for smoking-related cancers did not differ from that of the general population.

Conclusion The results indicate a weak but dose-related association between exposure to pesticides and risk for Parkinson's disease; however, the results were based on 28 cases and the possibility of no association cannot be ruled out.
\end{abstract}

Key terms Denmark; epidemiology; gardening; occupational health.

Parkinson's disease is a common neurodegenerative disorder engendered by loss of dopaminergic neurons in the substantia nigra pars compacta of the brain (1). The etiology of the disease is probably a complex interplay of aging, genetics, and the environment (2), except for a small proportion of cases that can be attributed to gene mutations (3). It has been suggested that environmental factors might cause a direct effect, such as a toxic agent causing cell death, or an indirect effect through DNA expression or repair processes (4).

Gardeners are exposed to a wide range of environmental factors, including pesticides, some of which have shown to be neurotoxic to humans (5). Although several studies have addressed an association between working in occupations with exposure to pesticides and the risk for Parkinson's disease, they mainly focused on farmers. No study has focused solely on professional gardeners. The aim of this study was to examine the risk for Parkinson's disease in a cohort of Danish gardeners exposed to pesticides.

\section{Methods}

\section{Study population}

The cohort comprised 3124 professional male gardeners identified from a cross-sectional file covering all members of the Danish Union of Gardeners. The gardeners worked primarily in greenhouses, nursery gardens, or public parks, gardens and cemeteries, and the majority were regularly exposed to a mixture of pesticides during their active working life (6). All the members of

1 Institute of Cancer Epidemiology, Danish Cancer Society, Copenhagen, Denmark.

2 Department of Occupational Medicine, Regional Hospital Herning, Herning, Denmark.

Correspondence to: Line Kenborg, Institute of Cancer Epidemiology, Danish Cancer Society, Strandboulevarden 49, 2100 Copenhagen, Denmark. [E-mail: kenborg@cancer.dk]. 
the cohort had a valid personal identification number, were working on 1 May 1975, and alive and living in Denmark on 1 January 1977 (baseline).

\section{Parkinson's disease and cancer}

We linked the cohort members with the files of the Danish National Hospital Register to identify those who had been diagnosed with Parkinson's disease (ICD-8 code 342 and ICD-10 code G20) when they were aged $\geq 35$ years. The Hospital Register contains data on all hospital admissions for somatic diseases in Denmark since 1977; information on outpatients and emergency ward contacts was added to the Register in 1995 (7). Only in- and outpatients with a primary diagnosis of Parkinson's disease were identified. For patients discharged more than once with this diagnosis, only the first record was retained and used as the date of diagnosis.

We also linked the study population to the Danish Cancer Registry to identify incident cases of the major smoking-related cancers [ie, of the lung (ICD-7 162; ICD-10 C33-C34 and C39), larynx (ICD-7 161; ICD-10 C32) and urinary bladder (ICD-7 181; ICD-10 C67)] (8). As previous studies have repeatedly found a protective effect of smoking on the risk for Parkinson's disease (9, 10 ), we included these cancers as proxies for smoking among gardeners.

\section{Statistical analysis}

Gardeners were followed for a primary diagnosis of Parkinson's disease from 1 January 1977 or when they reached 35 years until the earliest diagnosis of this disease, death, emigration, loss to follow-up, or 31 December 2008. We compared the observed numbers of first hospital contacts for a primary diagnosis of Parkinson's disease among gardeners with those expected from age-, gender- and calendar-period-specific rates for the general population in 1977-2008. The rates were calculated by multiplying the numbers of person-years for cohort members by the in- and outpatient rates for a primary diagnosis of Parkinson's disease of Danish men in 5-year age groups and calendar periods.

Similarly, we calculated the incidences of cancers of the lung, larynx and urinary bladder among the gardeners and compared them with those expected from the age- and calendar-period-specific incidence rates in the general male population. The observed and expected numbers were derived from the Danish Cancer Registry for the period 1977-2008.

Standardized hospitalization rate ratios (SHR) for Parkinson's disease were computed, as were standardized incidence rate ratios (SIR) for cancers of the lung, larynx, and urinary bladder. For each risk estimate, the associated $95 \%$ confidence interval $(95 \% \mathrm{CI})$ was calculated on the assumption of a Poisson distribution of the observed numbers.

As the working environment of gardeners and their exposure to pesticides has changed during the twentieth century, we also conducted a birth cohort analysis (gardeners born in 1900-1914, 1915-1934, or 1935-1958) to evaluate the presence of a time trend for risk of Parkinson's disease. Gardeners in the early birth cohort were $\geq 30$ years old in the period after World War II, when pesticide use became widespread. As heavy use began to decline in the 1960s, gardeners in the late birth cohort were not exposed to the same extent as their counterparts in the two earlier birth cohorts (11).

\section{Results}

The cohort consisted of 3124 gardeners born between 1900-1958, who accrued 68323 person-years of follow-up (range, 4 days to 32 years), with an average of 24.7 years (table 1 ).

During follow-up, 28 of the gardeners were hospitalized with a primary diagnosis of Parkinson's disease, while 24.5 were expected from the rates for the general population, yielding an overall slightly increased SHR of 1.14 (95\% CI 0.76-1.65) (table 1). When we stratified the analysis on the three birth cohorts, the risk estimate was 1.55 (95\% CI $0.77-2.77)$ for the early birth cohort (table 2).

In the analysis of smoking-related cancers among the gardeners, the risk estimate for lung cancer was close to that of the Danish population (SIR 1.03, 95\% CI 0.86-1.20) (table 3).

\section{Discussion}

In this follow-up study of 3124 professional gardeners, the overall risk for a first hospitalization for Parkinson's disease was close to that of the general Danish population. In the birth cohort most intensively exposed to pesticides, we observed 11 cases of Parkinson's disease when 7.5 were expected, a difference that did not reach statistical significance.

This is the first study, to our knowledge, to investigate the risk for Parkinson's disease among gardeners. Several studies have found positive associations between farming and Parkinson's disease (12-16), including a Danish study, in which men working in agriculture and horticulture had a significantly higher risk for a first hospital admission for Parkinson's disease (SHR 132, 95\% CI 111-156) than the general Danish population (17). It has been suggested that the increased risks of farmers 
Table 1. Selected characteristics of 3124 Danish professional gardeners

\begin{tabular}{lrr}
\hline Characteristics & Number & $\%$ \\
\hline Period of birth & & \\
1900-1914 & 501 & 16.0 \\
1915-1934 & 1185 & 37.9 \\
1935-1958 & 1438 & 46.0 \\
Censoring of follow-up due to & & \\
Parkinson's disease & 28 & 0.9 \\
Emigration / disappeared & 18 & 0.6 \\
Dead & 1529 & 48.9 \\
End of follow-up, 31 December 2008 & 1549 & 49.6 \\
Year of Parkinson's disease diagnosis & & \\
1977-1979 & 1 & 3.6 \\
1980-1989 & 12 & 42.9 \\
1990-1999 & 12 & 42.9 \\
2000-2006 & 3 & 10.7 \\
Diagnosis of Parkinson's disease obtained from & & \\
Outpatient clinic & 4 & 14.3 \\
Inpatient clinic & 24 & 85.7 \\
\hline
\end{tabular}

Table 2. Standardized hospitalization rate ratios (SHR) and 95\% confidence intervals $(95 \% \mathrm{Cl})$ for Parkinson's disease among 3124 Danish professional gardeners, by birth cohort

\begin{tabular}{lccc}
\hline Birth cohort & Observed cases & SHR & $95 \% \mathrm{Cl}$ \\
\hline All & 28 & 1.14 & $0.76-1.65$ \\
$1900-1914$ & 11 & 1.55 & $0.77-2.77$ \\
$1915-1934$ & 16 & 1.15 & $0.66-1.87$ \\
$1935-1958$ & 1 & 0.28 & $0.00-1.58$ \\
\hline
\end{tabular}

Table 3. Standardized incidence rate ratios (SIR) and 95\% confidence intervals $(95 \% \mathrm{Cl})$ for cancer of the lung, urinary bladder, and larynx among 3124 Danish professional gardeners

\begin{tabular}{lccc}
\hline Site of cancer & Observed cases & SIR & $95 \% \mathrm{Cl}$ \\
\hline Lung & 139 & 1.02 & $0.86-1.20$ \\
Larynx & 9 & 0.72 & $0.33-1.37$ \\
Urinary bladder & 59 & 0.82 & $0.62-1.05$ \\
\hline
\end{tabular}

and agricultural workers are related to exposure to pesticide $(17,18)$, and this hypothesis has been examined in several recent epidemiological studies, most of which found positive associations (18-27), while few were unable to find such effects (28-30). Four of the studies were cohort studies $(18,25-27)$, while the remaining had a case-control design. However, the results of the case-control studies might have been affected by differential recall by case status as suggested in a recent study of the potential for recall bias in case-control studies of pesticides and Parkinson's disease (31).

The exposure of Danish gardeners to pesticides was described by the Danish National Environmental Board (32) and in studies of their cancer risk $(6,11)$, showing that, in Denmark, gardeners have had more frequent and intense exposure to pesticides than any other occupational group (11), including farmers who usually spray crops only a few times a year. Furthermore, as most Danish male gardeners stay in the trade from a young age until retirement, they are considered to constitute a very stable job group. When the cohort of gardeners was established for the studies of cancer risks, it was estimated that one third had been directly exposed to pesticides, while the remainder has been indirectly exposed by skin contact with newly sprayed plants or by inhalation when working in newly sprayed areas (6). Several of the pesticides used by Danish gardeners have shown to be neurotoxic to humans, including organochlorines [eg, dieldrin, dichlorodiphenyltrichloroethane (DDT) and lindane], paraquat, organophosphates (eg, malathion) and dithiocarbamates (eg, maneb) $(5,11$, 30,33). Gardeners in the early birth cohort (born before 1915) were potentially exposed to the highly toxic pesticides introduced after World War II, which might have resulted in the observed elevated risks for certain neoplasms, such as soft tissue sarcoma and leukemia, found in an earlier study (11).

The strengths of our study include the long follow-up time (up to 32 years), complete follow-up of the cohort members, and ascertainment of diagnoses of Parkinson's disease and smoking-related cancers from national registers, thus minimizing the possibility of bias in selection of study subjects or reporting disease outcomes. The potential limitations of the study include the finding that, although Parkinson's disease is a common disorder, only 28 of the gardeners had a primary diagnosis of this disease during follow-up. This limited the statistical power of the study, especially for assessing trends in risks across birth cohorts. Furthermore, we did not have individual information on exposure to pesticides or smoking habits. Cigarette smoking has repeatedly been associated with a decreased risk for Parkinson's disease. In the analysis of smoking-related cancers, however, the risk for lung cancer did not differ from that of the general population, although the risk for urinary bladder and larynx cancer was slightly decreased, indicating neutral or slightly reduced smoking frequencies among gardeners.

The identification of cases with Parkinson's disease from a hospital register might have introduced some degree of disease misclassification, because a smaller unknown percentage of patients with secondary parkinsonism or symptomatic related diseases are discharged with a Parkinson's disease diagnosis. To minimize the inclusion of misdiagnosed gardeners, we only included those who had a primary diagnosis of Parkinson's disease during follow-up as this diagnosis is considered to be more accurate and reliable than a supplementary diagnosis. A previous study of patients with Parkinson's disease in Denmark showed that patients with such a diagnosis more often are diagnosed in a neurological department compared to patients with a supplementary diagnosis (34). We also lacked information on date of 
first symptoms. Most patients with Parkinson's disease begin drug treatment months to years before they are hospitalized with a primary diagnosis of Parkinson's disease (34), indicating a delay in diagnosis when solely identifying cases in a hospital register. Furthermore, when patients in the early phase of the disease are not in contact with either in- or outpatient clinics, less severe cases of Parkinson's disease were potentially not detected during follow-up. However, this also applies to the general Danish population, thus leading to nondifferential disease misclassification.

The gardeners were followed for Parkinson's disease from 1977 (the same year the Danish National Hospital Register was instituted), so some prevalent cases might have been registered in the first years. However, when we lagged the analysis by excluding the first three years of follow-up (1977-1979), the overall risk estimate changed only slightly (SHR $1.17,95 \%$ CI $0.77-1.70$ ).

Since all the gardeners in the cohort were working at the time of inclusion, they constitute a healthier group than the average population, which includes both the unemployed and invalids. Parkinson's disease mainly affects older people, thus it is unlikely that the disease has influenced employment earlier in life, but might have caused a selection out of the workforce due to the physical limitations of the movement disorder. This healthy worker survivor effect tends to underestimate an exposure-disease relationship, thus potentially biasing the risk estimate toward the null. However, the strength of the healthy worker effect tends to diminish with length of time since entry (35), so the long follow-up time in this study might have weakened the effect, if there was any.

In conclusion, the study indicates a weak but doserelated association between exposure to pesticides and Parkinson's disease. Further, larger studies are warranted to clarify whether gardeners exposed to pesticides have a higher risk for Parkinson's disease.

\section{Acknowledgments}

We thank Andrea Meersohn, Institute of Cancer Epidemiology, Danish Society, Copenhagen, Denmark for conducting the statistical analyses.

\section{References}

1. Obeso JA, Rodriguez-Oroz MC, Goetz CG, Marin C, Kordower JH, Rodriguez M, et al. Missing pieces in the Parkinson's disease puzzle. Nat Med. 2010;6:653-61 doi:10.1038/nm.2165.
2. Henchcliffe C, Beal MF. Mitochondrial biology and oxidative stress in Parkinson disease pathogenesis. Nat Clin Pract Neurol. 2008;4:600-9. doi:10.1038/ncpneuro0924.

3. de Lau LM, Breteler MM. Epidemiology of Parkinson's disease. Lancet Neurol. 2006;5:525-35. doi:10.1016/S14744422(06)70471-9.

4. Tanner CM. Advances in environmental epidemiology. Mov Disord. 2010;25 Suppl 1:S58-S62. doi:10.1002/mds.22721.

5. Costa LG, Giordano G, Guizzetti M, Vitalone A. Neurotoxicity of pesticides: a brief review. Front Biosci. 2008;13:1240-9. doi: $10.2741 / 2758$.

6. Hansen ES, Hasle H, Lander F. A cohort study on cancer incidence among Danish gardeners. Am J Ind Med. 1992;21:651-60. doi:10.1002/ajim.4700210505.

7. Andersen TF, Madsen M, Jorgensen J, Mellemkjoer L, Olsen JH. The Danish National Hospital Register. A valuable source of data for modern health sciences. Dan Med Bull. 1999;46:263-8.

8. International Agency for Research on Cancer (IARC). Tobacco smoke and involuntary smoking. Lyon: IARC; 2004. IARC monographs on the evaluation of carcinogenic risks to human, vol. 83.

9. Chen H, Huang X, Guo X, Mailman RB, Park Y, Kamel F, et al. Smoking duration, intensity, and risk of Parkinson disease. Neurology. 2010;74:878-84.doi:10.1212/ WNL.0b013e3181d55f38.

10. Ritz B, Ascherio A, Checkoway H, Marder KS, Nelson LM, Rocca WA, et al. Pooled analysis of tobacco use and risk of Parkinson disease. Arch Neurol. 2007;64:990-7. doi:10.1001/ archneur.64.7.990.

11. Hansen ES, Lander F, Lauritsen JM. Time trends in cancer risk and pesticide exposure, a long-term follow-up of Danish gardeners. Scand J Work Environ Health. 2007;33:465-9.

12. Goldman SM, Tanner CM, Olanow CW, Watts RL, Field $\mathrm{RD}$, Langston JW. Occupation and parkinsonism in three movement disorders clinics. Neurology. 2005;65:1430-5. doi:10.1212/01.wnl.0000180361.74060.70.

13. Gorell JM, Peterson EL, Rybicki BA, Johnson CC. Multiple risk factors for Parkinson's disease. J Neurol Sci. 2004;217:169-74. doi:10.1016/j.jns.2003.09.014.

14. Park J, Yoo CI, Sim CS, Kim HK, Kim JW, Jeon BS, et al. Occupations and Parkinson's disease: a multi-center casecontrol study in South Korea. Neurotoxicology. 2005;26:99105. doi:10.1016/j.neuro.2004.07.001.

15. Park RM, Schulte PA, Bowman JD, Walker JT, Bondy SC, Yost $\mathrm{MG}$, et al. Potential occupational risks for neurodegenerative diseases. Am J Ind Med. 2005;48:63-77. doi:10.1002/ ajim. 20178.

16. Zorzon M, Capus L, Pellegrino A, Cazzato G, Zivadinov R. Familial and environmental risk factors in Parkinson's disease: a case-control study in north-east Italy. Acta Neurol Scand. 2002;105:77-82. doi:10.1034/j.1600-0404.2002.10040.x.

17. Tuchsen F, Jensen AA. Agricultural work and the risk of Parkinson's disease in Denmark, 1981-1993. Scand J Work Environ Health. 2000;26:359-62. 
18. Ascherio A, Chen H, Weisskopf MG, O'Reilly E, McCullough ML, Calle EE, et al. Pesticide exposure and risk for Parkinson's disease. Ann Neurol. 2006;60:197-203. doi:10.1002/ ana.20904.

19. Costello S, Cockburn M, Bronstein J, Zhang X, Ritz B. Parkinson's disease and residential exposure to maneb and paraquat from agricultural applications in the central valley of California. Am J Epidemiol. 2009;169:919-26. doi:10.1093/ aje/kwp006.

20. Dick FD, De PG, Ahmadi A, Scott NW, Prescott GJ, Bennett J, et al. Environmental risk factors for Parkinson's disease and parkinsonism: the Geoparkinson study. Occup Environ Med. 2007;64:666-72. doi:10.1136/oem.2006.027003.

21. Dutheil F, Beaune P, Tzourio C, Loriot MA, Elbaz A. Interaction between $\mathrm{ABCB} 1$ and professional exposure to organochlorine insecticides in Parkinson disease. Arch Neurol. 2010;67:739-45. doi:10.1001/archneurol.2010.101.

22. Elbaz A, Clavel J, Rathouz PJ, Moisan F, Galanaud JP, Delemotte B, et al. Professional exposure to pesticides and Parkinson disease. Ann Neurol. 2009;66:494-504. doi:10.1002/ana.21717.

23. Frigerio R, Sanft KR, Grossardt BR, Peterson BJ, Elbaz A, Bower JH, et al. Chemical exposures and Parkinson's disease: a population-based case-control study. Mov Disord. 2006;21:1688-92. doi:10.1002/mds.21009.

24. Hancock DB, Martin ER, Mayhew GM, Stajich JM, Jewett R, Stacy MA, et al. Pesticide exposure and risk of Parkinson's disease: a family-based case-control study. BMC Neurol. 2008;8:6. doi:10.1186/1471-2377-8-6.

25. Kamel F, Tanner C, Umbach D, Hoppin J, Alavanja M, Blair A, et al. Pesticide exposure and self-reported Parkinson's disease in the agricultural health study. Am J Epidemiol. 2007;165:364-74. doi:10.1093/aje/kwk024.

26. Baldi I, Lebailly P, Mohammed-Brahim B, Letenneur L, Dartigues JF, Brochard P. Neurodegenerative diseases and exposure to pesticides in the elderly. Am J Epidemiol. 2003;157:409-14. doi:10.1093/aje/kwf216.
27. Petrovitch H, Ross GW, Abbott RD, Sanderson WT, Sharp DS, Tanner CM et al. Plantation work and risk of Parkinson disease in a population-based longitudinal study. Arch Neurol. 2002;59:1787-92. doi:10.1001/archneur.59.11.1787.

28. Firestone JA, Smith-Weller T, Franklin G, Swanson P, Longstreth WT, Jr.,Checkoway H. Pesticides and risk of Parkinson disease: a population-based case-control study. Arch Neurol. 2005;62:91-5. doi:10.1001/archneur.62.1.91.

29. Firestone JA, Lundin JI, Powers KM, Smith-Weller T, Franklin GM, Swanson PD, et al. Occupational factors and risk of Parkinson's disease: A population-based case-control study. Am J Ind Med. 2009;53:217-23.

30. Wright JM, Keller-Byrne J. Environmental determinants of Parkinson's disease. Arch Environ Occup Health. 2005;60:328. doi:10.3200/AEOH.60.1.32-38.

31. Rugbjerg K, Harris MA, Shen H, Marion SA, Tsui JK, Teschke K. Pesticide exposure and risk of Parkinson's disease - a population-based case-control study evaluating the potential for recall bias. Scand J Work Environ Health. 2011;37(5):427-436.

32. Stubsgaard E, Simonsen JG, Winther P, Outzen S. Pesticidanvendelser i forskellige brancher. [Uses of pesticides in different industries.] Copenhagen: Knowledge Center for Ground Pollution and Danish Environmental Protection Agency; 2000.

33. Krieger R (ed). Hayes' Handbook of Pesticide Toxicology. 3 ed. USA: Elsevier; 2010.

34. Rugbjerg K, Friis S, Ritz B, Schernhammer ES, Korbo L, Olsen JH. Autoimmune disease and risk for Parkinson disease: a population-based case-control study. Neurology. 2009;73:1462-8. doi:10.1212/WNL.0b013e3181c06635.

35. Pearce N, Checkoway H, Shy C. Time-related factors as potential confounders and effect modifiers in studies based on an occupational cohort. Scand J Work Environ Health. 1986:12:97-107.

Received for publication: 11 March 2011 